\title{
The French Ambulatory Cesarean Section: Technique and Interest
}

\author{
Ami Olivier ${ }^{1,2^{*}}$, Fauck Mathieu ${ }^{3}$, Simon Bénédicte ${ }^{4}$, Benhamou Richard ${ }^{1}$,
Hubert $^{6}$, Menard Agnes ${ }^{2}$, Ravina Jacques Henri ${ }^{2}$ and Fauck Denis ${ }^{2}$
${ }^{1}$ Ramsay Générale de Santé, Clinique de la Muette, 46 rue Nicolo, 75016 Paris, France \\ ${ }^{2}$ Clinique Sainte Thérèse, 9 rue Gustave Doré, 75017 Paris, France \\ ${ }^{3}$ Centre hospitalier Robert Bisson - 4, rue Roger Aini, BP 97223, 14107 Lisieux, France \\ ${ }^{4}$ Hôpital privé Versailles les Franciscaines, 7 Bis Rue de la Porte de Buc, 78000 Versailles, France \\ ${ }^{5}$ Polyclinic Santa Maria, 57 Avenue de la Californie, 06200 Nice, France \\ ${ }^{6}$ Polyclinique La Pergola, 75 allée des ailes, 03200 Vichy, France
}

\author{
Publication History: \\ Received: March 19, 2017 \\ Accepted: September 20, 2017 \\ Published: September 22, 2017 \\ Keywords: \\ Cesarean section, Hysterotomy, \\ Anesthesia, Obstetrical, Pain, \\ Minimally Invasive Surgical \\ Procedures
} be discharged within 24 hours.

The FAUCS procedure may issue in a significant diminution of morbidity, with a mean hospital stay duration of 3,1 days while the mean estimation of ability to be discharged was 1,3 days.

\section{Introduction}

The unwanted but however unavoidable worldwide rise in the frequency of caesarean sections is responsible for a remarkable increase of certain complications if compared to vaginal delivery (1). The operative intervention itself is accompanied by an elevated occurrence of post-surgical complications and post-operative pain, an extended recovery time and so delayed return to the patient's daily activities and last but not least by a non-negligible rise in medical care costs $(2,3)$. The biosurgery concept, first described by Manhès et al. (4), requires a minimal approach, seeking anatomical cleavage planes and the least trauma possible, respecting the surrounding cellular engineering and ecosystem, providing solutions capable of stimulating and channeling the body's own regenerative reactions solely in the places where they are needed, with no artificial fixation procedures. A modified extraperitoneal method of caesarean section was described in the middle of the 90's by Fauck et al. [5-7], which basically consists of a paramedian vertical opening of the aponeurosis $[8,9]$, a left paravesical extraperitoneal approach of the uterus $[10,11]$, a purse string suture of the uterine wall [12-15] and a glued skin closure [16-18]. This technique can be used on an ambulatory mode, and have been used over 20 years by several surgeons in France. The extraperitonisation principles have been recently studied prospectively and their interest demonstrated [19]. The present paper describes the French AmbUlatory Cesarean Section (FAUCS) technique, and reports in what extent this alternative procedure, respecting biosurgery principles, results in a significant decrease in the inconveniences mentioned above.

\section{Methods}

From January 1997 to January 2017 a FAUCS technique was performed in 3341 cases by 6 obstetrical surgeons in France. A retrospective study was performed to evaluate the impact on morbidity. The mean age of the patients was 31.8 years; ranging from 19 to 48 years old. The criteria of inclusion consisted of an indication for planned or emergency caesarean section after 34 weeks of amenorrhea regardless of cervical dilatation. The mean operating time, mean duration of hospital stay, and the postoperative remarkable benefits and complications were evaluated for each operator with a survey.

\section{Surgical Technique}

\section{Preoperative preparation}

The standard asepsis protocol for both elective and emergency cesarean sections remained unchanged. No preoperative urinary catheterization was required (see below).

\section{Regional anaesthesia}

Reduced doses of anaesthetics were applied in order to ensure the rapid recovery of the patient's autonomy meanwhile maintaining an adequate analgesic effect during operation [20]. In case of scheduled caesarean sections EMLA $^{\star}$ cream (lidocaine and prilocaine) was applied as a first step for local cutaneous analgesia at the puncture point [21]. The use of a fine 27 Gauge epidural catheter allowed the rapid mobilization of the patient meanwhile reduced the risk of a post-lumbar puncture syndrome. From $2 \mathrm{ml}$ of $5 \mathrm{mg} / \mathrm{ml}(10$ $\mathrm{mg}$ ) of ropivacaine combined with $0.5 \mathrm{ml}(5 \mu \mathrm{g})$ of Sufentanyl were

"Corresponding Author: Dr. Olivier Ami, Ramsay Générale de Santé, Clinique de la Muette, 46 rue Nicolo, 75016 Paris, France, Tel: +33 6611439 24, Tel: +33 1787678 52; E-mail: olivier.ami@cnpgo.org

Citation: Olivier A, Mathieu F, Bénédicte S, Richard B, Jean-Jacques C, et al. (2017) The French Ambulatory Cesarean Section: Technique and Interest. Int J Gynecol Clin Pract 4: 131. doi: https://doi.org/10.15344/2394-4986/2017/131

Copyright: (C) 2017 Olivier et al. This is an open-access article distributed under the terms of the Creative Commons Attribution License, which permits unrestricted use, distribution, and reproduction in any medium, provided the original author and source are credited. 
Citation: Olivier A, Mathieu F, Bénédicte S, Richard B, Jean-Jacques C, et al. (2017) The French Ambulatory Cesarean Section: Technique and Interest. Int J Gynecol Clin Pract 4: 131. doi: https://doi.org/10.15344/2394-4986/2017/131

Page 2 of 6

administrated, for a patient of $1,50 \mathrm{~m}$ height (and $2 \mathrm{mg}$ of ropivacaine every $10 \mathrm{~cm}$ above $1,50 \mathrm{~m}$ of height). In case of insufficiency, an intra venous injection of $1 \mathrm{mg}$ of Midazolam and $10 \mathrm{mg}$ of Ketamine could be administered.

The surgical analgesia lasted 1 hour, which correlated with the duration of the surgery and established a complete sensory and incomplete motor block due to which the patient could be mobilized at once and left the operating room in a wheelchair after 45 minutes. If emergency caesarean section was indicated in course of labour the formerly initiated epidural was intensified as usual.

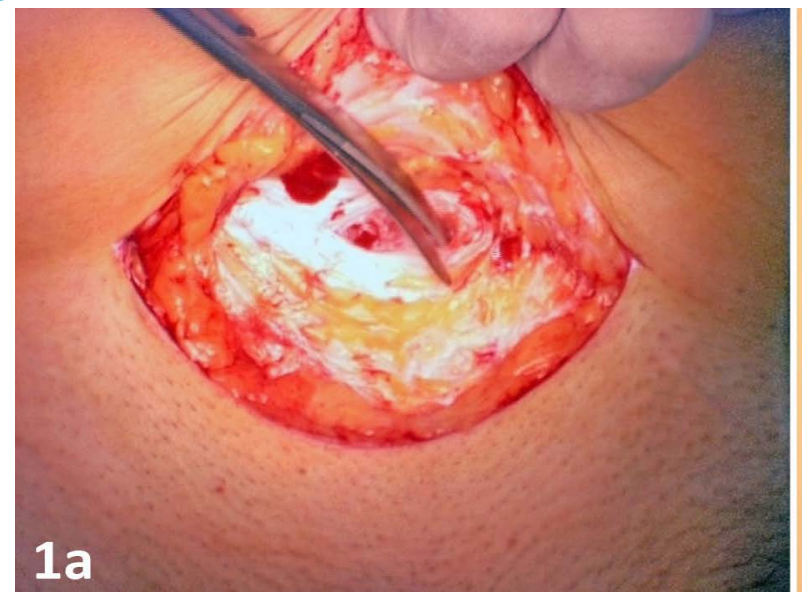
Figure 1: (1a)Aspect of the skin arciform incision. The adipose layer is not separated. (1b) Size landmarks are indicated, and the anterior
aponeurosissheath of rectus abdominis is opened transversaly on a short distance $(2 \mathrm{~cm})$ centered by the linea alba.
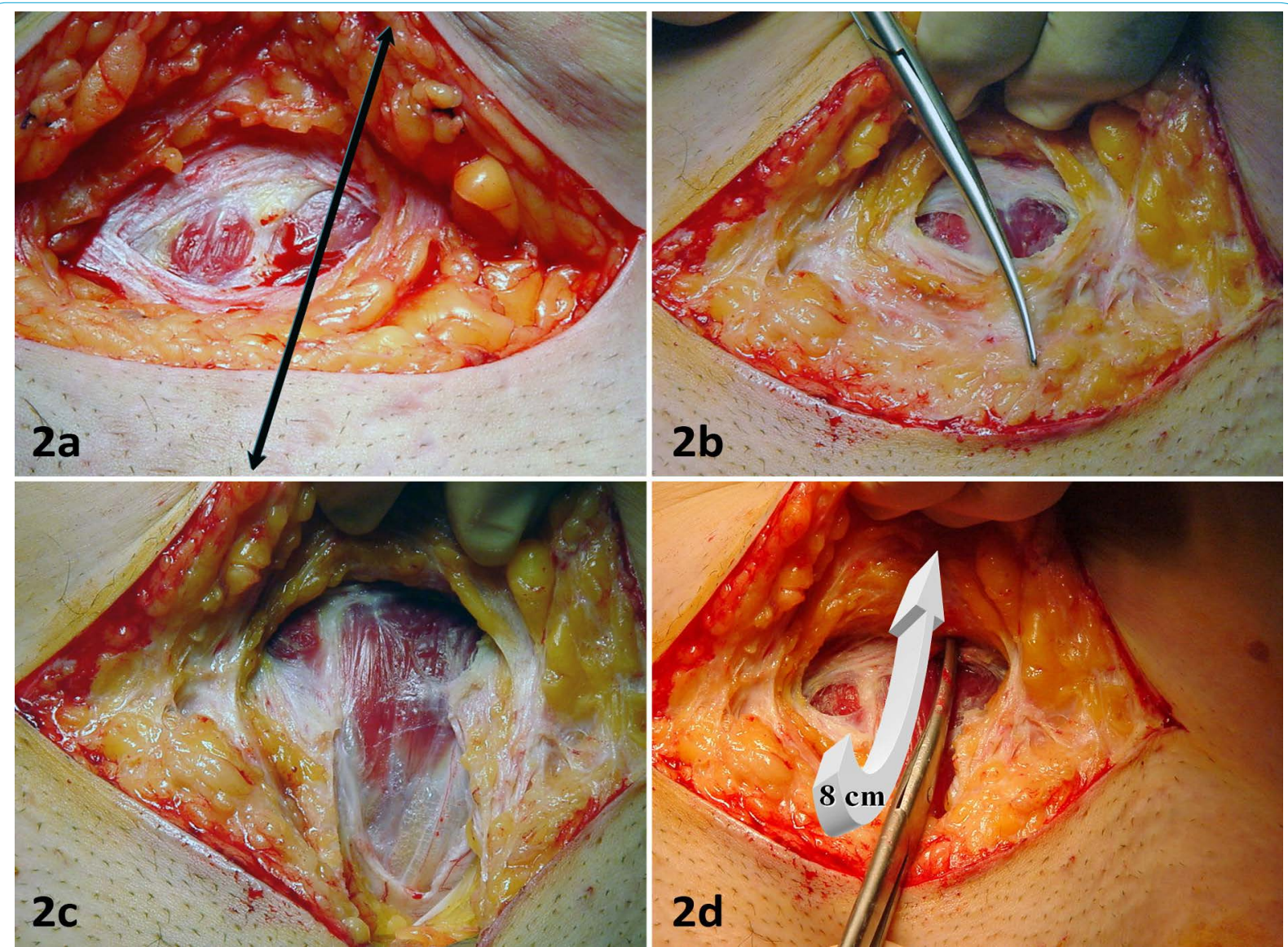

(2a) Vertical paramedian opening of the rectus abdominis' aponeurosis anterior sheath. (2b, 2c and $2 d)$ The scissor made incision stretches $6 \mathrm{~cm}$ towards the pubis and $8 \mathrm{~cm}$ towards the navel. 
Citation: Olivier A, Mathieu F, Bénédicte S, Richard B, Jean-Jacques C, et al. (2017) The French Ambulatory Cesarean Section: Technique and Interest. Int J Gynecol Clin Pract 4: 131. doi: https://doi.org/10.15344/2394-4986/2017/131

Page 3 of 6

\section{Vertical paramedian aponeurotic opening}

A two centimeters long cold scalpel incision is performed horizontally on the linea alba, centimeters above the skin, incising the anterior aponeurosis of the rectus abdominis muscle (Figure 2). The aponeurosis is opened also vertically along the left edge of the white line : the scissor made incision stretches $6 \mathrm{~cm}$ towards the pubis and $8 \mathrm{~cm}$ towards the navel thus forming a vertical cruciform paramedian opening. The left rectus abdominis muscle is deflected to the left with a retractor so to expose the anterior wall of the bladder.

\section{Extraperitoneal left paravesical approach}

The prevesical connective tissue layer is opened with curved scissors in order to facilitate the dissection (Figure 3). The operator approaches the retropubic space leading the fingers along the left paravesical route. The bladder is pushed and held to the right using a visible part of the left vesico-umbilical artery as a guide. It is essential that the patient urinate before the operation so the bladder can be easily identified due to the small urine residues. The extra-peritoneal approach with a totally empty catheterized or an excessively full bladder is only advised to operators already familiar with the technique in order to avoid eventual bladder injuries. described below present no problem for skilled operators. Unfavorable posterior presentation must be rotated manually so to obtain a more ideal anterior occipital position for the extraction. The use of forceps or spatulas is highly recommended in order to facilitate the extraction. In the event of dystocia of the soft parietal region the uterine incision can be enlarged at any time, e.g. by a Mouchel incision. In case of breech presentation, the fetus is extracted with the back in posterior position and the fetal nose and mouth are brought in front of the skin incision to allow the child to start breathing and thus providing the surgeon with ample time to extract the head gently. One of the most important key factors of the extraperitoneal extraction is the appropriate pressing on the base of the uterus. The assistant starts to press only at the request of the surgeon and must maintain a continuous pressure since each release may result in a failure of fetal progression.

\section{Delivery}

The process of delivery does not differ from the classical caesarean. The administration of uterotonics like carbetocin ( $\mathrm{Pabal}^{\circ} 100 \mu \mathrm{g}$ i.v.) or oxytocin (Syntocinon ${ }^{\bullet} 10 \mathrm{IU}$ i.v.) is recommended right after cutting the umbilical cord [22].
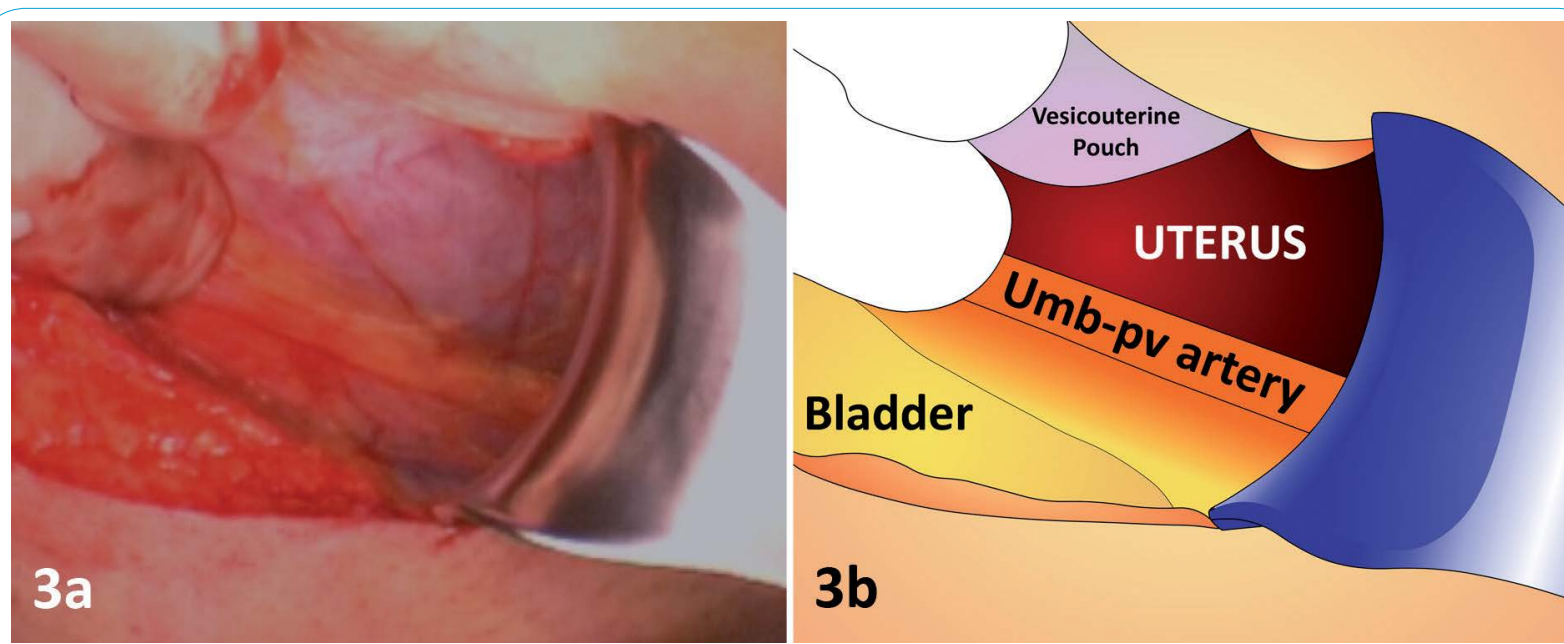

Figure 3: (3a) Aspect of the extraperitoneal approach. (3b) Hysterotomy is performed between the intact intervesicouterine pouch, and the left umbilicoprevesical artery.

\section{Hysterotomy}

The lower segment of the uterus is approached within the anatomical triangle defined by the prevesical umbilical artery medially, by the iliac vessels laterally and by the vesico-uterine peritoneal fold on the top (Figure 4). Low segment hysterotomy is performed under the peritoneal cul-de-sac at the same level as for transperitoneal caesarean section. After the cautious preparation of the subserous layers a one centimeter long horizontal incision is made in the myometrium. Following the artificial rupture of the membranes the initial incision is enlarged by the fingers pulling apart the edges vertically.

\section{Fetal extraction}

The combination of a horizontal skin incision, a vertical aponeurotic opening and the extraperitoneal approach results in an unusual and relatively small extraction field and so requires the surgeon to be well experienced in caesarean fetal extraction. The eventual difficulties

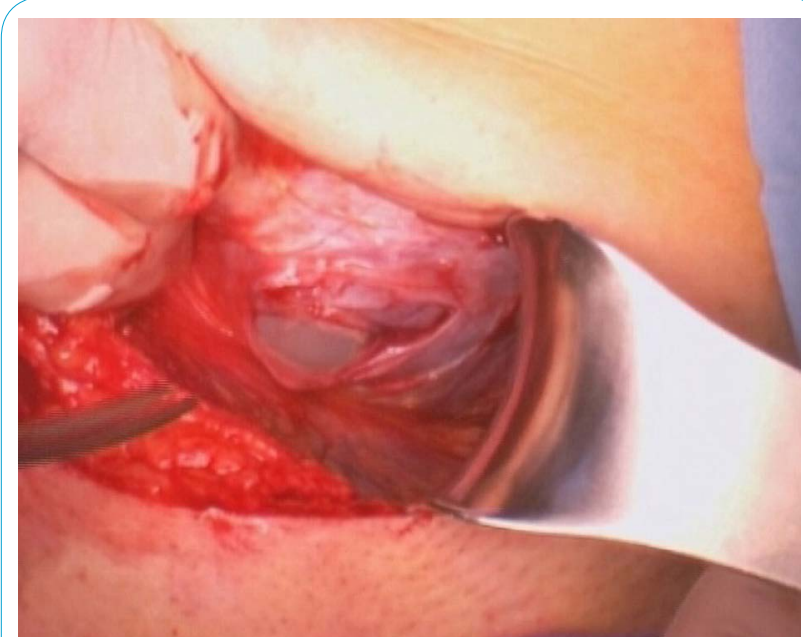

Figure 4: Aspect and position of the hysterotomy. 
Citation: Olivier A, Mathieu F, Bénédicte S, Richard B, Jean-Jacques C, et al. (2017) The French Ambulatory Cesarean Section: Technique and Interest. Int J Gynecol Clin Pract 4: 131. doi: https://doi.org/10.15344/2394-4986/2017/131

Page 4 of 6

\section{Suture of the uterine incision}

The purse suture of the uterine incision allows a good control of bleeding and decreases the length of the uterine wound while increases its thickness (Figure 5).

The slowly absorbed Vicryl 1 suture with a large round needle is introduced intramyometrially right above the endometrium. The suture starts in one corner and proceeds along the lower then the upper edge returning back to the incision point. Subserous layer is closed upon using the same thread in order to cover the purse suture and to complete the haemostasis while increasing the wound thickness.
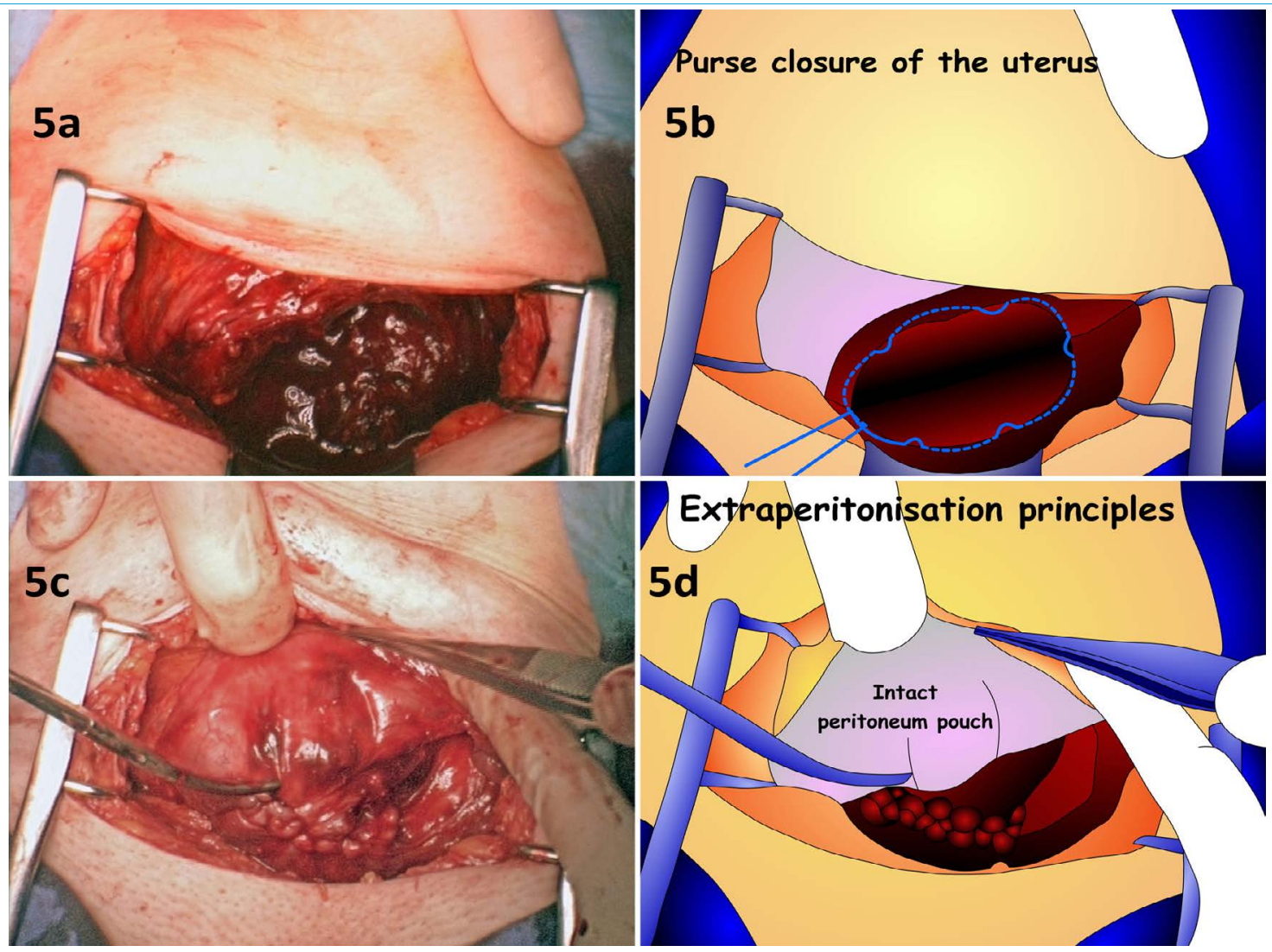

Figure 5: (5a) Aspect of the hysterotomy before suturing. (5b) Path of the uterine purse closure of the uterus. (5b) Post hysterotomy purse closure aspect. (5d) Scheme of the intact peritoneum pouch, and finished closure of the uterine wall.
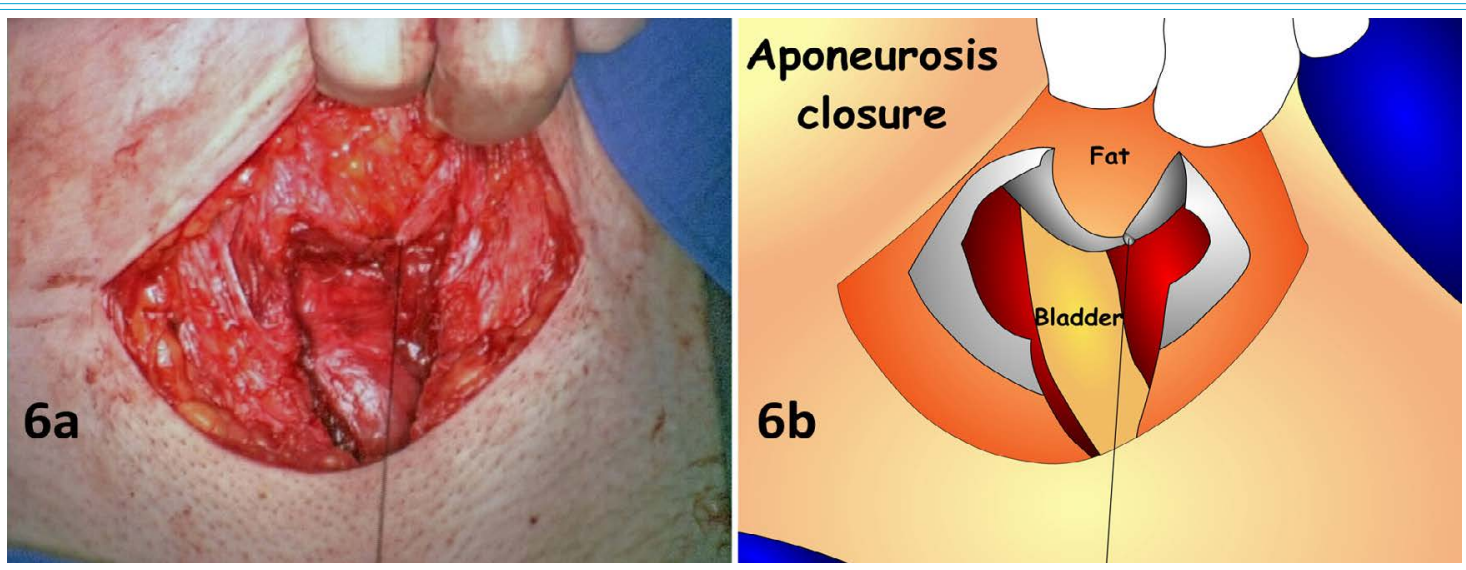

Figure 6: (6a) As fat tissues were not splitted from the aponeurosis, the aponeurosis closure begins with its posterior surface exposed. (6b) This scheme shows the everted upper edges to help visual control. The continuous suture starts in the upper corner and leads along the posterior surface of the anterior aponeurosis of the rectus abdominis muscle back to the initial incision point. 
Citation: Olivier A, Mathieu F, Bénédicte S, Richard B, Jean-Jacques C, et al. (2017) The French Ambulatory Cesarean Section: Technique and Interest. Int J Gynecol Clin Pract 4: 131. doi: https://doi.org/10.15344/2394-4986/2017/131

Page 5 of 6

\section{Skin closure}

The subcutaneous layers are united along the edges of the superficial fascia stitches using rapidly absorbing braided Vicryl $2 / 0$. The edges of the skin incision are held together and glued with the dermal adhesive [16]. The result is a cosmetically pleasing scar which needs no dressing after the operation.

\section{Postoperative management}

A two-hour long surveillance period in the recovery room is mandatory like in case of all kinds of surgery.

Postoperative pain management is usually based on the administration of acetaminophen (paracetamol) $1 \mathrm{~g}$ intravenous relayed to oral form $1 \mathrm{~g}$ every 6 hours during the immediate postoperative period.

If necessary more potent drugs can be added such as the nonsteroidal ketoprofen $50 \mathrm{mg} 3$ times daily or the central analgesic nefopam 1 ampoule of $20 \mathrm{mg} / 2 \mathrm{ml}$ every 6 hours orally with a lump of sugar.

The need for even stronger analgesics must be considered as an indicator of post-surgical complications which must be identified. The use of opioids is avoidable if the principles of analgesia recommended by the WHO are carefully followed.

As mentioned above urinary catheterization is unnecessary in the absence of complete motor nerve bloc. Patients are mobilized right after the intervention and encouraged to urinate spontaneously.

With careful pain release and omitting opioids in the post-operative period the patient is prevented from entering in the too well-known vicious circle of having enormous and apparently opioid requiring pain because of her opioid induced incapacity to empty her full thus aching bladder.

In the absence of opening of the peritoneal wall the blood and amniotic fluid cannot get into contact with the intraperitoneal cavity which minimises the risk of a reflex paralytic ileus and the development of peritoneal adhesions and consequent intestinal occlusions.

Patients can eat after the obligatory two hours of surveillance.

Careful pain management and the elimination of opiates forestall the adverse gastrointestinal symptoms like nausea and vomiting often seen after caesareans.

The patients' early mobilisation takes place in the presence of a doctor with the consent of the anaesthetist before leaving the recovery room. They must get up slowly and gradually in 90 seconds at least and paying particular attention to eventual headache, dizziness, nausea or any other signs of hypotension. Patients have to be warned about the mild pain which may occur when changing position but once standing they usually feel very little discomfort and can walk easily.

Patients regain their full autonomy as soon as after vaginal birth and may take care of their newborns right after leaving the recovery room. Besides increasing the patients' comfort this is the existing best way to prevent post-surgical thromboembolic events.
Thanks to the glued skin cut, mothers can have a shower immediately after the intervention. This type of skin closure does not need any particular care or dressing. It is less painful and prone to infection and produces less scarring than sutured or stapled closure. The glue is gradually eliminated by desquamation in approximately ten days thus reducing the time of wound management (no follow-up visits for removal are required).

\section{Results}

3441 extra-peritoneal caesarean sections were carried out by 6 different surgeons in 6 obstetrical centers between 1997 and 2017. During this retrospective study, 146 medical charts had uncompleted data about painkillers consumption.

544 cases $(16,28 \%)$ could be discharged within 24 hours and the mean hospital stay was 3,1 days, depending on the newborn's day of discharge but not because of the procedure. As a comparison, the duration of the national mean hospital stay with the Stark's method in France was 6 days in 2015.

The mean operation time was 23 minutes. On the first day of hospital stay, $92,94 \%$ of the patients could be eligible for an hospital discharge (Table 1), and the mean estimation of real ability to be discharged was 1,3 days in our series..

99 patients required morphine in the postoperative period $(2.9 \%)$ and 698 patients required no painkillers in the postoperative period $(20.9 \%)$

We observed 11 cases of bladder injury $(0.3 \%)$ mainly around the training period of surgeons and linked to severe adherences. 7 cases of hematoma in the retropubic space $(0.2 \%$ - not requiring any further surgery) and 4 cases of parietal abscesses $(0.1 \%)$. The frequency of superficial hematomas and steatonecrosis was comparable to the conventional technique. No gastrointestinal, vascular, ureteral or any other serious eventually life-threatening lesions occurred.

Within the considered period 380 repeat FAUCS extraperitoneal caesareans were performed without complications; in 6 cases triple repeats and in 1 case a quadruple repeat. At the relaparotomy we could observe a thickened scar tissue in the prevesical space and performed routinely the preventive ligation and section of the left vesico-umbilical artery to avoid uncontrollable bleeding from its eventual tearing and the development of a consequent retropubic hematoma mentioned above. Half of the repetitive cases couldn't be strictly extraperitoneal because of adherences.

In the cases of extreme emergencies or life-threatening situations pre-existing to the caesarean indication, where a swift fetal extraction was paramount, a standard transperitoneal caesarean procedure such as the Stark method was used by all the obstetricians of this study to avoid incriminating the extraperitoneal technique.

\section{Discussion}

As described above, the FAUCS method described in the present paper significantly improves patients' postoperative comfort providing them almost immediately with their autonomy, thus reducing morbidity and shortening the time of hospital stay. 
Citation: Olivier A, Mathieu F, Bénédicte S, Richard B, Jean-Jacques C, et al. (2017) The French Ambulatory Cesarean Section: Technique and Interest. Int J Gynecol Clin Pract 4: 131. doi: https://doi.org/10.15344/2394-4986/2017/131

Page 6 of 6

\begin{tabular}{|c|c|c|c|c|c|c|c|}
\hline Days of hospital stay & 1 & 2 & 3 & 4 & 5 & 6 & 7 \\
\hline Number of patient discharged & $\begin{array}{l}544 \\
(16,28 \%)\end{array}$ & $\begin{array}{l}694 \\
(20,77 \%)\end{array}$ & $\begin{array}{l}895 \\
(26,79 \%)\end{array}$ & $\begin{array}{l}581 \\
(17,39 \%)\end{array}$ & $\begin{array}{l}376 \\
(11,25 \%)\end{array}$ & $\begin{array}{l}232 \\
(6,94 \%)\end{array}$ & $\begin{array}{l}19 \\
(0,57 \%)\end{array}$ \\
\hline Patients still in the hospital & $\begin{array}{l}3341 \\
(100 \%)\end{array}$ & $\begin{array}{l}2797 \\
(83,72 \%)\end{array}$ & $\begin{array}{l}2103 \\
(62,95 \%)\end{array}$ & $\begin{array}{l}1208 \\
(36,16 \%)\end{array}$ & $\begin{array}{l}627 \\
(18,77 \%)\end{array}$ & $\begin{array}{l}251 \\
(7,51 \%)\end{array}$ & $\begin{array}{l}19 \\
(0,57 \%)\end{array}$ \\
\hline \multicolumn{8}{|l|}{ Mean painkillers consumption } \\
\hline Acetaminophen & $80,28 \%$ & $89,10 \%$ & $32,67 \%$ & $22,68 \%$ & $29,19 \%$ & $26,29 \%$ & $10,53 \%$ \\
\hline Nsaid & $77,19 \%$ & $87,95 \%$ & $20,26 \%$ & $18,38 \%$ & $13,72 \%$ & $7,57 \%$ & $5,26 \%$ \\
\hline Nefopam & $10,14 \%$ & $3,57 \%$ & $4,51 \%$ & $0,73 \%$ & $0 \%$ & $0 \%$ & $0 \%$ \\
\hline Morphin & $2,96 \%$ & $1,86 \%$ & $0,10 \%$ & $0 \%$ & $0 \%$ & $0 \%$ & $0 \%$ \\
\hline Urinary drainage & $\begin{array}{l}35 \\
(1,05 \%)\end{array}$ & $\begin{array}{l}11 \\
(0,33 \%)\end{array}$ & $\begin{array}{l}11 \\
(0,33 \%)\end{array}$ & $3(0,09 \%)$ & 0 & 0 & 0 \\
\hline $\begin{array}{l}\text { Mobility equivalent to a patient delivered vaginally } \\
\text { without episiotomy }\end{array}$ & $\begin{array}{l}3068 \\
(91,83 \%)\end{array}$ & $\begin{array}{l}3126 \\
(93,56 \%)\end{array}$ & $\begin{array}{l}3167 \\
(94,79 \%)\end{array}$ & $\begin{array}{l}3202 \\
(95,84 \%)\end{array}$ & $\begin{array}{l}3298 \\
(98,71 \%)\end{array}$ & $\begin{array}{l}3322 \\
(99,43 \%)\end{array}$ & $\begin{array}{l}3341 \\
(100 \%)\end{array}$ \\
\hline $\begin{array}{c}\text { Normal transit } 3 \text { hours after C-Section : normal meal, no } \\
\text { nausea }\end{array}$ & $\begin{array}{l}3239 \\
(96,95 \%)\end{array}$ & $\begin{array}{l}3287 \\
(98,38 \%)\end{array}$ & $\begin{array}{l}3338 \\
(99,91 \%)\end{array}$ & $\begin{array}{l}3340 \\
(99,97 \%)\end{array}$ & $\begin{array}{l}3340 \\
(99,97 \%)\end{array}$ & $\begin{array}{l}3340 \\
(99,97 \%)\end{array}$ & $\begin{array}{l}3340 \\
(99,97 \%)\end{array}$ \\
\hline Chose breastfeeding & $\begin{array}{l}2238 \\
(67 \%)\end{array}$ & $\begin{array}{l}2138 \\
(64 \%)\end{array}$ & $\begin{array}{l}2071 \\
(62 \%)\end{array}$ & $\begin{array}{l}2038 \\
(61 \%)\end{array}$ & $\begin{array}{l}2038 \\
(61 \%)\end{array}$ & $\begin{array}{l}2005 \\
(60 \%)\end{array}$ & $\begin{array}{l}1971 \\
(59 \%)\end{array}$ \\
\hline $\begin{array}{l}\text { Could feed the baby within } 3 \text { hours after C-Section } \\
\text { among patient who have chosen breastfeeding }\end{array}$ & $\begin{array}{l}2237 \\
(99,93 \%)\end{array}$ & $\begin{array}{l}2136 \\
(99,9 \%)\end{array}$ & $\begin{array}{l}2067 \\
(99,79 \%)\end{array}$ & $\begin{array}{l}2035 \\
(99,85 \%)\end{array}$ & $\begin{array}{l}2036 \\
(99,9 \%)\end{array}$ & $\begin{array}{l}2003 \\
(99,92 \%)\end{array}$ & $\begin{array}{l}1971 \\
(99,99 \%)\end{array}$ \\
\hline $\begin{array}{c}\text { No urinary drainage, no IV, No painreliefs other than } \\
\text { Step I, Walking normally, normal transit, normal meal, } \\
\text { can carry her baby : Could be discharged from a medical } \\
\text { point of view }\end{array}$ & $\begin{array}{l}3105 \\
(92,94 \%)\end{array}$ & $\begin{array}{l}2609 \\
(93,28 \%)\end{array}$ & $\begin{array}{l}2047 \\
(97,34 \%)\end{array}$ & $\begin{array}{l}1183 \\
(97,93 \%)\end{array}$ & $\begin{array}{l}614 \\
(97,93 \%)\end{array}$ & $\begin{array}{l}248 \\
(98,80 \%)\end{array}$ & $19(100 \%)$ \\
\hline
\end{tabular}

Table 1: On the first day of hospital stay, 92,94\% of the patients could be eligible for an hospital discharge, and the hospital stay was motivated only by the babies and/or home care services organisation before returning home.

The benefits of the FAUCS technique on digestion were preserved by the pain management which no longer involves the inconvenient side effects of opioids.

The absence of urinary drainage reduces the risk of nosocomial urinary infection and reduces mother's discomfort.

The intactness of the peritoneal cavity eliminates the risk of adhesions and postoperative ileus, as well as future infertility related to surgery. Patients can eat normally within 2 hours after surgery if there are no opioids added to the protocol.

The immediate mobilisation ensures the prevention of venous thromboembolism and favours the early mother and baby relation. The absence of peritoneum opening, and the early mobility after surgery could be considered to avoid postoperative anticoagulation if compression stockings are used.

5 surgeons of the study were trained by Dr Denis Fauck, and mentioned the importance of being trained to the FAUCS method through a fellowship training with an experienced surgeon.

\section{Conclusion}

FAUCS extraperitoneal caesarean section reduces morbidity issuing from the cesarean section and rather approaches the advantages of vaginal delivery if compared to the conventional transperitoneal caesarean section method. The FAUCS technique requires the thorough knowledge of pelvic surgical anatomy and obstetrical biomechanics applied to cesarean. For beginners, the training period with an experienced surgeon familiar to the FAUCS technique is highly recommended to avoid complications.

\section{Competing Interests}

The authors declare that they have no competing interests.

\section{References}

1. Declercq E, Cunningham DK, Johnson C, Sakala C (2008) Mothers' reports of postpartum pain associated with vaginal and cesarean deliveries: results of a national survey. Birth Berkeley Calif 35: 16-24.

2. Burrows LJ, Meyn LA, Weber AM (2004) Maternal morbidity associated with vaginal versus cesarean delivery. Obstet Gynecol 103: 907-912.

3. Traynor JD, Peaceman AM (198) Maternal hospital charges associated with trial of labor versus elective repeat cesarean section. Birth Berkeley Calif 25: 81-84

4. Manhes H, Lesec G, Rabischong B (1998) Biosurgery. First draft of a definition for a new philosophy in surgery. Rev Fr Mécanique 1: 53-54.

5. Fauck D, Ami O, Naett M, Ravina JH (2000) Comparative StudyExtraperitoneal Cesarean Section (CS) versus Vaginal Delivery. Int J Gynaecol Obstet Suppl.

6. Ravina JH, Fauck D, Menard A, Naett M, Ami O (2000) Césarienne extrapéritonéale, techniques, résultats. Arch Pediatr Organe Off Soc Francaise Pediatr 7: 1027-1028.

7. Ami O (2013) Extraperitoneal cesarean section technique [Internet]. Paris (France); (WATOG). Donaldson DR, Hegarty JH, Brennan TG, Guillou PJ, Finan PJ, et al. (1982) The lateral paramedian incision--experience with 850 cases. Br J Surg 69: 630-632.

8. Guillou PJ, Hall TJ, Donaldson DR, Broughton AC, Brennan TG (1980) Vertical abdominal incisions--a choice? Br J Surg 67: 395-399.

9. Norton JF (1946) A paravesical extraperitoneal cesarean section technique; with an analysis of 160 paravesical extraperitoneal cesarean sections. Am J Obstet Gynecol 51: 519-1526.

10. Norton JF, Mangone E (1950) Paravesical extraperitoneal cesarean section technic. Am J Surg 80: 902-905. 
Citation: Olivier A, Mathieu F, Bénédicte S, Richard B, Jean-Jacques C, et al. (2017) The French Ambulatory Cesarean Section: Technique and Interest. Int J Gynecol Clin Pract 4: 131. doi: https://doi.org/10.15344/2394-4986/2017/131

11. Chen C (2006) Laparoscopic myomectomy for large myomas. Int Surg 91: S77-S80.

12. Alessandrini F, Canosa C, De Filippo CM, Nasso G, Spatuzza P, et al. (2006) Repair of acute postinfarct posterior ventricular septal rupture without left ventriculotomy: a stable suture preserving left ventricular geometry. J Card Surg 21: 94-69.

13. Lee J-H, Cho D-H (2011) Myomectomy using purse-string suture during cesarean section. Arch Gynecol Obstet 283: 35-37.

14. Turan C, Büyükbayrak EE, Yilmaz AO, Karsidag YK, Pirimoglu M (2015) Purse-string double-layer closure: a novel technique for repairing the uterine incision during cesarean section. J Obstet Gynaecol Res 41: 565574.

15. Daykan $\mathrm{Y}$, Sharon-Weiner M, Pasternak $\mathrm{Y}$, Tzadikevitch-Geffen $\mathrm{K}$ Markovitch O, et al. (2017) Skin closure at cesarean delivery, glue vs subcuticular sutures: a randomized controlled trial. Am J Obstet Gynecol 216: 406.e1-406.e5.

16. Croce P, Frigoli A, Perotti D, Di Mario M (2007) [Cesarean section, techniques and skin suture materials]. Minerva Ginecol 59: 595-599.

17. Westcott JM, Crockett L, Qiu F, Berg TG (2016) Effect of skin coverage method following subcuticular suturing on wound infection rates at cesarean delivery. The Journal of Maternal-Fetal \& Neonatal Medicine 30: 1-3.

18. Tappauf C, Schest E, Reif P, Lang U, Tamussino K, et al. (2013) Extraperitoneal versus transperitoneal cesarean section: a prospective randomized comparison of surgical morbidity. Am J Obstet Gynecol 209: 338. e1-338.e8.

19. Camorcia M, Capogna G, Berritta C, Columb MO (2007) The relative potencies for motor block after intrathecal ropivacaine, levobupivacaine, and bupivacaine. Anesth Analg 104: 904-907.

20. Elson JA, Paech MJ (1995) EMLA cream prior to insertion of elective epidurals. Anaesth Intensive Care 23: 339-341.

21. Borruto F, Treisser A, Comparetto C (2009) Utilization of carbetocin for prevention of postpartum hemorrhage after cesarean section: a randomized clinical trial. Arch Gynecol Obstet 280: 707-712. 